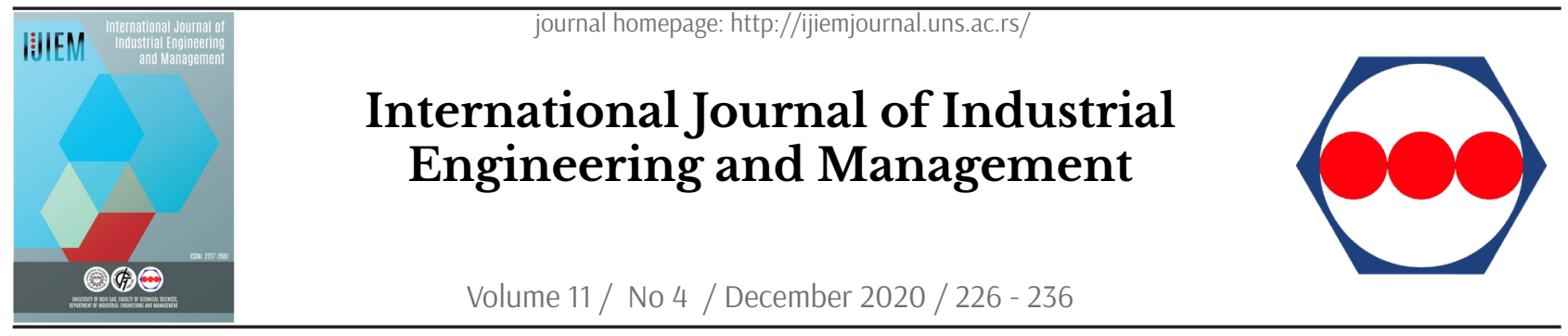

Original research article

\title{
Revisiting the online shopper's behaviour in Indonesia: The role of trust and perceived benefit
}

\author{
W. Widyastuti ${ }^{a, b *}$, S. Hartini $^{\text {b }}$, Y. Artanti $a, b$ \\ a Universitas Negeri Surabaya, Department of Management, Surabaya, Indonesia; \\ ${ }^{b}$ Universitas Airlangga, Department of Management, Surabaya, Indonesia
}

\section{A B STRACT}

This study attempts to analyze the factors that influence attitudes toward online shopping in Indonesia. The population in this study is consumers who have experience buying products online through social media or e-commerce. The implication of the study is enriching the behavioural marketing studies about factors that influence online product purchases and suggest the marketers create a more effective marketing strategy based on different customer level of trust. The study results showed that perceived benefit and trust are the driving factors of consumer attitudes to make online purchases. In this study, perceived benefit functions as a mediator of trust influence on attitude. This study reveals that high levels of trust influence consumer attitudes toward online shopping while at low levels of trust, consumer attitudes will be more influenced by perceived benefits.

\section{ARTICLE INFO}

Article history:

Received August 20, 2020

Revised November 18, 2020

Accepted November 18, 2020

Published online December 3, 2020

Keywords:

Perceived benefit;

Trust;

Consumer attitude;

Online shopping

*Corresponding author:

Widyastuti Widyastuti

widyastuti@unesa.ac.id

\section{Introduction}

Industrial Revolution 4.0 always brought a new era to human civilization in creating the social, economic and politic that ready to face science and technology development [1]. Industrial Revolution that brings a massive change in economics marked by the optimum utilization of information technology and communication to produce digitalization in every aspect of life.

Online buying and selling is a form of information technology development. The traditional buying and selling process requires a meeting between sellers and buyers which buyers can see the goods directly has shifted along with the increasingly widespread online shop. Online shopping system is considered more efficient because it saves customers time [2]-[4]. By exploring just one e-commerce, consumers can move between stores to get the product they want without having to spend time travelling from one store to another. Online purchases are also not limited by time and place [5]. Transactions with e-commerce can be done 24 hours a day in a different week than when shopping at an offline store that is limited by store hours.

Besides e-commerce also offers other advantages 
such as ease of finding product variations [6]-[9] and price comparisons [4], consumers can choose various types of products with various brands provided by e-commerce. E-commerce is the right place to shop because consumers can find the same product at a lower price by comparing various websites simultaneously and also because of the many promotional programs offered by e-commerce suits for price-sensitive consumers.

Consumer doubts make online purchases because of a lack of trust in the online system. It is because online purchases are unable to meet buyers and see the purchased goods [10]. Some researchers state that the factor that consumers dislike in online shopping is that consumers cannot touch and feel or try the products to be purchased [11]. Uncertainties and the risks involved in online transactions put trust as an essential factor that needs attention [12], [13]. Privacy and trust issues could hold consumers from making online purchases [11]. Some of the consumer concerns about the leakage of personal information, online fraud, inconsistency between the quality of the product ordered, and the quality desired delivery that failed [4]. Security of financial transactions and issues related to the privacy of personal information are essential things in the online shopping system [12], [14].

Thus, trust is an important thing that needs to be considered in the online system, and the lack of trust will affect the attitudes of consumers in online shopping [15], [16]. Trust helps consumers in building favourable expectations and suits vendor expectation. Lack of trust will affect consumer attitudes in online shopping [16].

Besides trust, perceived benefit is also a factor that consumers consider when making online purchases. When consumers perceive the benefits gained after making online purchases based on awareness of current technological developments which are all done online, then they will have a positive attitude towards the online system. Following the opinion [17] which explains the decision making process on online consumer behaviour usually begins with an awareness of the situation that will have a positive impact on attitude and ends with the decision to buy and repurchase.

This study aims to analyze the consumers attitude towards online shopping. According to [18], consumers' attitudes towards something is the extent to which individuals have favourable or unfavourable evaluations or judgments of behaviour that must be followed up. A person's behaviour is influenced by the experience he has gained so far. Trust expressed by behaviour is considered as the attitude of consumers towards online shopping [19]. Measuring attitude, in the context of online shopping, is essential because attitude has a positive impact on online shopping intentions and is considered the most influential factor [15].

This research also formulates the role of trust and perceived benefits in enhancing consumers' positive attitudes towards online shopping. Even though online shopping has significant risks, there are a few benefits that could be gained by buyer and seller. For this reason, trust is a significant factor that must be considered in online trading [20].

Although research related to the influence of trust on attitudes and perceived benefits have been widely done, the relationship between trust and perceived benefits between researchers shows a different model. Some researchers stated that trust has a positive effect on perceived benefits which further determines consumer attitudes and intentions to shop online [21]-[23], whereas [24] shows that the consumers' perceived benefit of mobile banking will lead to trust in the mobile banking service. Meanwhile, trust and perceived benefit are not interconnected, but both act as independent variables that function as antecedent attitudes and online shopping behaviour [5], [25], [26].

This study examines how consumer attitudes towards online shopping, where there are two main contributions expected. First, researchers tested the role of trust and perceived benefits on consumer attitudes towards online shopping. It is well known that trust is an essential factor in online systems that have a significant risk of uncertainty. Lack of trust in online transactions and e-retailers is generally a significant obstacle in adopting online shopping [27].

Second, the researcher divided the belief into two groups based on the average so that the high belief group and the low belief group were obtained. Based on this group, the researchers tried to reveal the role of each level of trust in attitudes towards online shopping.

\section{Literature review}

\subsection{Attitude toward online shopping}

Attitude is one of the factors that influence purchasing decisions. According to [28], attitude is an overall consumer evaluation of a concept which can be classified into two categories, namely attitudes towards an object and attitudes towards behaviour. 
Attitude towards behaviour is a form of positive or negative evaluation of consumers towards relevant behaviour, and consists of strong beliefs in consumers about the consequences felt when performing the behaviour [19]. [29] states that consumer attitudes will influence the intention to shop online and ultimately determine the occurrence of a transaction. When compared to beliefs and values, attitudes are more comfortable to change so that it becomes the focus of marketers in attracting consumers [30].

According to [31] in Theory of Planned Behaviour, a person's inner belief in the consequences of doing an action can affect attitudes toward actual behaviour. Each individual will have different beliefs depending on individual characteristics and experiences that have been felt [32]. The main factors that determine the success of a company's online marketing strategy are attitudes, perceptions and motivation [33]. Attitude will be established through motivation, perception and learning that lead to decision-making [30]. Several things affect consumer attitudes on online shopping, including personal and psychological factors. Personal factors are indicated by perceived benefits, while psychological factors are indicated by the perceived trust [5].

\subsection{Trust}

Trust is one's willingness to believe in the actions taken by others. Trust is included in the characteristics of consumers which can directly affect the attitude of consumers [17]. Trust is also a person's belief in the credibility and reliability of vendors where consumers can interact with marketers via the web. This interaction is expected to fulfil consumers' desire to make financial, product and psychological exchanges [34].

Trust in e-commerce is more important than other factors because the online business environment is difficult to verify or control [16]. Research on consumer trust has been carried out by experts such as [5], [14], [20], [25], [35]. The experts concluded that trust is an essential factor in conducting online transactions. Consumers must be sure that their online transactions will not bring financial and non-financial losses. When consumers feel confident, it will lead to attitudes toward online shopping behaviour. The result of the studies [5], [36], [37] shows that trust determines a person's attitude to make a purchase.

Delays in delivery and complexity in transactions can prevent consumers from making purchases using the online system. However, if the complexity in the transaction process turns out to be able to protect consumer privacy, it will increase consumer confidence in the online system, and the end can provide a positive perception of consumer attitudes. [38].

Several studies have concluded that trust has a positive effect on perceived benefit. When consumers trust to make online transactions, they will experience benefits such as time efficiency, cost reduction of finding products or services and secure purchases [22]. Consumers could save on search costs and comparison processes and even increase their productivity (for example, better purchasing decisions in a short period) in the purchasing process using an online system when they can transact with trusted online shops [39].

By purchasing products through a trusted website, consumers can get various benefits from online transactions such as cost savings, time savings, convenience, broad product choices, and the convenience of obtaining shopping information. The high trust in the web / online shop will increase the consumers' perception of the benefits. Based on the description, the hypotheses in this study are:

H1a: Trust has a positive effect on attitude toward online shopping

H1b: High level of trust has a positive effect on attitude toward online shopping

H2a: Trust has a positive effect on perceived benefit

H2b: High level of trust has a positive effect on perceived benefit

\subsection{Perceived Benefit}

Perceived Benefit focuses on consumers' perceptions of the benefits obtained on a product [40]. Consumer's perceived benefits is beliefs about the extent to which consumers will feel better in online transactions with certain websites [25]. The benefits felt by consumers will motivate to make online purchases. Meanwhile, [30] describes the perceived benefits as the number of profits that meet the needs or desires of consumers.

Online shopping provides various conveniences for consumers. The key benefit of online shopping is it can be done anytime and anywhere. Consumers often do not need much effort to find details about the desired product, and comparing rates from one store to another does not take much time. As suggested by [5], customers do not need to feel ashamed when they only window shopping, finding specific product or price details and do not end up purchasing the product. 
Several studies related to perceived benefits have been conducted by researchers such as [5], [25], [41]. The results show that the perceived benefits of consumers can influence the positive attitude of consumers towards online shopping. Perceived benefits play an essential role in the formation of consumer attitudes [5], [25]. For consumers familiar with online systems, the perceived benefits are a significant driver and help in shaping positive and beneficial attitudes towards online shopping. Based on the results of previous studies, the hypotheses in this study are:

H3: Perceived benefit has a positive effect on attitudes towards online shopping.

\section{Methodology}

The population in this study is consumers who have experience buying products online. There are no restrictions on the types of products purchased by respondents. Sampling uses a convenience sample technique, which is sampling without specific considerations but only based on convenience based on previous research that examines consumer attitudes [5], [42]. Sample in this research were 140 respondents. The questionnaires were created in Google form and distributed online through WhatsApp and e-mail.

Questionnaire in this study was measured by Likert Scale with a range of 1 to 7 , which shows the attitude of "Strongly Disagree" to "Strongly Agree". Attitudes toward online shopping are measured based on research indicator from [5], [43], [44]. Perceived benefits are measured using statement items from research [5], [41]. Furthermore, trust is measured using statement items from research [5], [36]. To know the effect of the level of trust on attitudes, the trust will be divided into two groups based on the average answers obtained from the questionnaire. The level

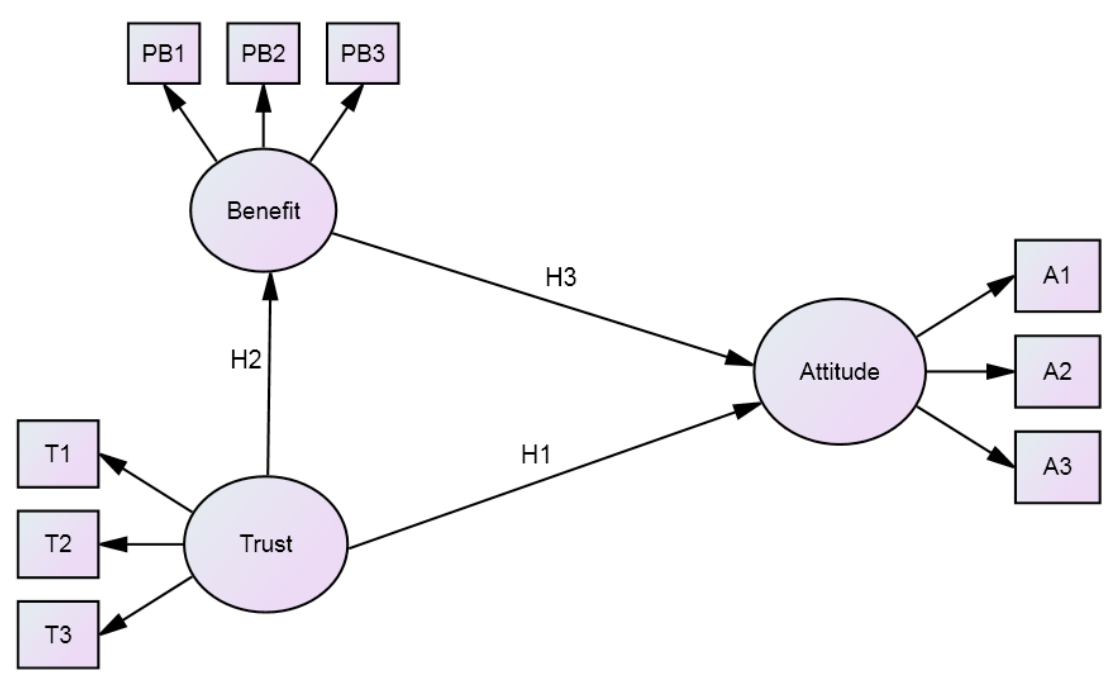

Figure 1. Research Model

Table 1. Question List

\begin{tabular}{ll}
\hline Indicators & Questions \\
\hline Perceived Benefi & Shopping at an online shop makes it easy for me to buy a variety of products. \\
& Shopping at an online shop can be done at any time. \\
& Shopping at the online shop can be done at home. \\
\hline & I believe that an online shop can provide good service. \\
& I believe that an online shop will protect information related to my finances f om being \\
Trust & hacked. \\
& I believe that an online shop will not sell my personal information (e.g. e-mail, telephone \\
& number, name) to others. \\
\hline Attitud & Shopping online is a good idea. \\
& Shopping online shop is better than shopping offlin \\
& Shopping online is a fun thing to do \\
\hline
\end{tabular}


of trust is high if the value of the answers is above the average value, and the level of trust is low if the value of the answers is below the average value.

\section{Results}

\subsection{Characteristic of Respondent Demography}

Table 2 shows the characteristics of the respondents in this study. Most respondents were male with a bachelor degree as their highest education level. More than half of respondents are generation $\mathrm{Y}$ aged between 20 - 39 years. This shows that Generation $\mathrm{Y}$ is accustomed to using the internet in doing their activities. In this research, most of the respondent is a student. Students are used to using the internet in everyday life, including online shopping.

\subsection{Construct Validity}

According to [45], construct validity can be used to assess the validity of measurement theory. With construct validity, researchers can assess the extent to which a set of items measured using a questionnaire can accurately reflect underlying construct theory. Construct validity testing can be performed using Confirmatory Factor Analysis (CFA) [45]. The loading factor value is something that needs to be considered in measuring validity. A factor loading value of more than 0.5 means the indicator used is a representation of the variables in the study.

In addition to using factor loading, validity can also be seen through convergent validity by calculat- ing the value of AVE (average variance extracted) and CR (construct reliability). An AVE value of 0.5 or more is a good condition and shows adequate convergence. AVE of less than 0.5 indicates that, on average, items that are present in a latent factor have more errors than the same variant. Meanwhile, CR is expected to have a value greater than or equal to 0.7 . High CR values indicate that there is internal consistency, which means that all measurements consistently represent the same latent construct [45]. Table 2 follows the results of loading factors using CFA.

The CFA loading factor in Table 3 shows the value above 0.5 . It means the questionnaire can be used because these indicators already represent the variables in this study. Besides, all constructs have an AVE value of more than 0.5 and have a $C R$ value of more than 0.7. Meanwhile, for the value of goodness of fit, all have more values than the required conditions $(\mathrm{GFI}=0.913 ; \mathrm{CFI}=0.939 ; \mathrm{TLI}=0.909)$, which is higher than 0.90 [45]. The value of RMSEA $=0.116$ is higher than 0.08 , but the $\mathrm{RMR}=0.077$ has a smaller value than the provision of less than 0.10 . This shows that in this study, there is a match of data with the model and the model form can be quite good.

\subsection{Discriminant Validity}

Discriminant validity is used to test whether a construct or variable is different from other constructs or variables in the model [45]. Discriminant validity testing is done by comparing the AVE value for the two constructs with the square correlation value between the two constructs. The results of data processing in table 2 show that the AVE value for Perceived Ben-

Table 2. Characteristic of Respondent Demography

\begin{tabular}{llll}
\hline & & Frequency & Percentage \\
\hline \multirow{2}{*}{ Gender } & Female & 53 & 37.86 \\
& Male & 87 & 62.14 \\
\hline \multirow{3}{*}{ Education } & High School & 47 & 33.57 \\
& Undergraduate & 51.43 \\
& Graduate & 58 & 25.00 \\
\hline \multirow{3}{*}{ Occupation } & Student & 35 & 38.57 \\
& Civil Servant & 54 & 17.14 \\
& Employee & 24 & 24.29 \\
Age & Entrepreneur & 34 & 5.00 \\
& Others & 7 & 15.00 \\
\hline
\end{tabular}


efit and Trust is 0.735 and 0.650 , which is greater than the squared correlated value between the two variables, which is 0.127 . Furthermore, Trust and Attitude each have an AVE of 0.650 and 0.610, which is greater than the correlated square value between the two, which is 0.540 . The last one is Perceived Benefit and Attitude, where both have AVE of 0.735 and 0.610 , respectively. The square correlated value between Perceived Benefit and Attitude is 0.464. Based on the description above, it can be concluded that there is no problem of discriminant validity in the constructs in this study because all AVE values are more than the construct correlated square values.

\subsection{Test of Hypothesis}

Hypothesis testing is done by analyzing the path in the structural model. The results of the Structural Equation Model processing are presented in table 4 below.

The result of the path test on the structural model shows that trust has a positive and significant effect on perceived benefit ( $\mathrm{p}$-value $=.00$ ) with an estimated value of 0.357 , proving that $\mathrm{Hla}$ is accepted. Likewise, the influence of trust on attitude toward online shopping has an estimated value of 0.563 and a p-value of .00. Trust has a positive and significant effect on attitude so that H2a is accepted. Furthermore,

Table 3. The Result of Construct Validity and Discriminant Validity

\begin{tabular}{|c|c|c|c|}
\hline Construct and Indikator & CFA Loading & AVE & $\begin{array}{l}\text { Composite } \\
\text { Reliability (CR) }\end{array}$ \\
\hline \multicolumn{4}{|l|}{ Perceived Benefi } \\
\hline $\begin{array}{l}\text { Shopping at an online shop makes it easy for me to buy a variety of } \\
\text { products }\end{array}$ & 0.849 & \multirow{3}{*}{0.735} & \multirow{3}{*}{0.904} \\
\hline Shopping at an online shop can be done at any time & 0.892 & & \\
\hline Shopping at the online shop can be done at home & 0.830 & & \\
\hline \multicolumn{4}{|l|}{ Trust } \\
\hline I believe that an online shop can provide good service & 0.680 & \multirow{3}{*}{0.650} & \multirow{3}{*}{0.795} \\
\hline $\begin{array}{l}\text { I believe that an online shop will protect information related to my finan - } \\
\text { es from being hacked }\end{array}$ & 0.890 & & \\
\hline $\begin{array}{l}\text { I believe that an online shop will not sell my personal information } \\
\text { (e.g. e-mail, telephone number, name) to others }\end{array}$ & 0.834 & & \\
\hline \multicolumn{4}{|l|}{ Attitude t ward online shopping } \\
\hline Shopping online is a good idea & 0.812 & \multirow{3}{*}{0.610} & \multirow{3}{*}{0.761} \\
\hline Shopping online shop is better than shopping offli & 0.744 & & \\
\hline Shopping online is a fun thing to do & 0.784 & & \\
\hline The goodness of fit indice & & $\begin{array}{l}\mathrm{GFI}=0 \\
\mathrm{RMR}=\end{array}$ & $\begin{array}{l}=0.940 ; \\
\text { MSEA }=0.115\end{array}$ \\
\hline
\end{tabular}

Table 4. Test of Hypothesis

\begin{tabular}{|c|c|c|c|c|c|c|}
\hline Hypothesis & Paths & & & Estimate & $\mathrm{p}$ & Result \\
\hline $\mathrm{H} 1_{\mathrm{a}}$ & Trust & $\rightarrow$ & Perceived benefi & 0.357 & $0.00^{* *}$ & Accepted \\
\hline $\mathrm{H} 2_{\mathrm{a}}$ & Trust & $\rightarrow$ & Attitud & 0.563 & $0.00^{* *}$ & Accepted \\
\hline $\mathrm{H} 3$ & Perceived benefi & $\rightarrow$ & Attitud & 0.480 & $0.00^{* *}$ & Accepted \\
\hline Goodness of Fit & Cut-off & & & & & \\
\hline GFI $: 0.910$ & $>0.90$ & & & & & \\
\hline AGFI : 0.831 & $>0.80$ & & & & & \\
\hline CFI $: 0.940$ & $>0.90$ & & & & & \\
\hline RMR : 0.073 & $<0.10$ & & & & & \\
\hline RMSEA : 0.115 & $<0.08$ & & & & & \\
\hline Significance ** $p<0.0$ & & & & & & \\
\hline
\end{tabular}


perceived benefit also has a positive effect on trust $(\mathrm{p}$-value $=.00)$ with an estimated value of 0.480 , proving that $\mathrm{H} 3$ is received.

Observing from the suitability of the model, then the model used in this study is appropriate because the results of the suitability of the model (GFI, AGFI, CFI) have a value higher than the specified limit value [45]. Compare to perceived benefit; trust has a greater influence on attitude with an estimated value of 0.563. Structural model test results also show that trust has an indirect effect on attitude through perceived benefit.

In addition, this research also aims to reveal how the degree of trust in online shopping affects customer attitudes. Therefore, trust is divided into two parts: a high level of trust and a low level of trust. The distribution is based on the average value, which is 4.78 , of the respondents' responses. A high level of trust was shown by the value above 4,78, and the low level of trust was shown by value below 4,78 is low. There are 76 respondents with values below the average, and above the average are the remaining 64 individuals. The following is a summary of the structural model's outcomes depending on the degree of consumer trust.

Based on Table 5, it can be seen that at a high level of trust, trust influences consumer attitudes toward online shopping (significance 0.05) with an estimated value of 0.880 and influences perceived benefit (significance 0.10 ) with an estimated value of 0.362 . At this level, attitude toward online shopping only influenced by the trust.

Meanwhile, when someone has a low level of trust, trust does not affect the perceived benefit. So, at the low level of trust, online shopping attitude is influenced by trust and perceived benefits. Comparing with trust that at a low level of trust, the perceived benefit has dominant effects on attitude with an estimated value of 0.643 .

According to [45], the model used in this study is moderate because the results of the suitability of the model (GFI, AGFI) have a value lower than the specified limit value, but the value of CFI is higher than 0.90. The value of RMSEA $=0.077$ and RMR $=0.075$ are smaller than the stipulation. This shows that the model between high trust level and lower trust level is appropriate.

\section{Discussion}

In today's digital era, it is undeniable that e-commerce has a broad impact on the people's economy. The increasing number of online shops shows that people are starting to realize the benefits of online shopping. The results of this study support other studies conducted by [5], [22], [23], [46]. The study also states that perceived benefit has a significant effect on attitude toward online shopping. Meanwhile, [47] found that perceived benefit is a determining factor for consumer attitudes in the use of mobile banking. Besides, perceived benefit is one of the factors that consumers consider in intention to use mobile banking services [48]. The existence of an online shop provides benefits that have been sought by consumers, such as time efficiency and ease of transactions.

Perceived benefit in this study influences in determining attitude toward online shopping. The higher the benefits felt by the customer, their attitude shown will be more positive. Perceived benefit is the value sought and obtained by online consumers in every online transaction that very important for future electronic marketing strategies [5]. Also, from the

Table 5. Hypothesis testing is based on the level of trust

\begin{tabular}{|c|c|c|c|c|c|c|c|}
\hline \multirow{2}{*}{ Hypothesis } & \multirow{2}{*}{ Paths } & & & \multicolumn{2}{|c|}{ High Trust } & \multicolumn{2}{|c|}{ Low Trust } \\
\hline & & & & Estimate & p & Estimate & $\mathrm{p}$ \\
\hline $\mathrm{H} 1_{b}$ & Trust & $\rightarrow$ & Perceived benefi & 0.362 & $0.076^{*}$ & -0.064 & 0.649 \\
\hline $\mathrm{H} 2_{b}$ & Trust & $\rightarrow$ & Attitud & 0.880 & $0.00^{* *}$ & 0.334 & $0.020^{* *}$ \\
\hline $\mathrm{H} 3$ & Perceived benefi & $\rightarrow$ & Attitud & 0.243 & 0.130 & 0.643 & $0.00^{* *}$ \\
\hline Goodness of Fit & Cut-off & & & & & & \\
\hline GFI $: 0.884$ & $>0.90$ & & & & & & \\
\hline AGFI : 0.782 & $>0.80$ & & & & & & \\
\hline CFI $: 0.914$ & $>0.90$ & & & & & & \\
\hline RMR : 0.075 & $<0.10$ & & & & & & \\
\hline RMSEA : 0.077 & $<0.08$ & & & & & & \\
\hline Significance ${ }^{*} p<0.10 ; * * p<0.0$ & & & & & & & \\
\hline
\end{tabular}


perspective of business strategy, perceived benefit reflects dynamic strategic capabilities that are vital for competing in the online market industry.

Perceived benefit also acts as a mediator connecting the influence between trust and attitude. These results support the research conducted by [22]. When consumers already have trust in a particular online shop, they will feel the benefits of using an online shop. Consumers will feel that shopping online will save their time [2], [3], can be done anytime [5], consumers can also get a variety of product choices [46] and get the ease of doing transactions [22]. With this convenience, it will ultimately encourage a positive attitude towards online shopping.

Trust is an essential factor in buying and selling online. Trust in this research is a primary antecedent of attitude toward online shopping. The results of this study are in line with research [5], [15], [22], which states that trust has a significant effect on attitude toward online shopping. Trust is a significant factor in attitude toward online shopping [15]. The higher the consumer's trust, the more positive their attitude toward online shopping. Customers' trust in the company's ability to meet their needs and desires is more than trusting good intentions of the company to influence consumer purchase intentions [49]. At the same time, the opposite result was revealed by [50], which stated that trust did not affect consumer attitudes on online shopping in Pakistan.

Trust has a positive effect on the perceived benefits of online channels [21]. When consumers have trust in online shop services and have trust that online shops can maintain the privacy of data and transactions that will be carried out, consumers' perceptions of the benefits are felt when making purchases using the online system. The advantage of saving time, shopping can be done at any time without leaving the house will bring up a positive attitude of consumers in online shopping. According to [51], consumer trust in shopping websites will increase along with the spent time in this activity, so they will get more benefits from the shopping process, and they are more likely to make shopping decisions.

The results of this study reveal that the level of trust plays a significant role in fostering consumer attitudes in online shopping. When consumers have a high level of trust above the average, then consumers will have a positive attitude towards online shopping and also have a positive perception of the benefits to be gained by doing online shopping. This is in line with research conducted by [5], [35], [52], [53] which states that the trust influences consumer attitudes towards online shopping because of what is occurring in an online system cannot be seen clearly. Consumers would feel a higher risk when using an online system that utilizes intangible and heterogeneous internet services, compared to transactions conducted face to face [54]. Thus, trust becomes an essential factor in fostering consumer attitudes on online shopping.

The existence of consumer trust in the website and online shop in providing the best service can provide benefits to consumers [26]. The ability of e-commerce to provide appropriate information can increase trust in online systems. E-commerce needs to convey information about the details of products sold, price, as well as the guarantee of a refund or damaged goods. As stated by [55] that consumers will see the benefits of shopping online if e-commerce can increase security, can protect consumer priva$\mathrm{cy}$, and is responsive to consumer desires. The trust only influences consumers who have a high level of trust, their attitudes towards online purchases. Trust is the main factor for consumers in this group. Consumers trust in online systems (trust in the honesty of marketers and financial transactions) will lead to a positive attitude and will further encourage the online purchasing decision process. In this condition, e-commerce can convince consumers of its ability to protect personal data, prevent consumers from transaction fraud and be able to provide the best service. E-commerce needs to always maintain consumer trust by sending products according to what is in the product catalogue, not cheating in prices, providing timely services and responding to consumer complaints quickly.

Meanwhile, at a low level of trust, it turns out that trust has a role towards attitude but does not have a role towards perceived benefit. In this condition, attitude is influenced by trust and perceived benefit, which is the perceived benefits have a more dominant influence than trust. In this group, consumer attitudes towards online shopping are more determined by the perceived benefits obtained when using the online system. The perceived benefits of consumers will be the ease of use of the online system, the ease of finding product variations and the time efficiency that will arouse the positive attitude of consumers in online shopping. With this positive attitude, it is hoped that it can lead to consumer buying behaviour. The advantages in terms of price, product diversity has a positive influence on online shopping attitudes [56].

The whole process of buying and selling online requires a high level of trust. In the selection of goods to be purchased, consumers cannot feel, hold or try the item. Nevertheless, online shopping consumers 
only get information about the desired item through pictures displayed by sellers on their online shop pages. Furthermore, consumers must also believe that the seller will keep the address, telephone number, or card number that is used in the transaction confidential. Finally, at the time of delivery, the consumer must have confidence that the products received are the same as the product ordered through the online system and delivered based on the delivery period written in the agreement (term and condition). Trust owned by consumers will encourage consumers to have a positive attitude. Thus, there will be repeated purchasing decisions that reflect their loyalty.

\section{Conclusion and Implication}

This study attempts to analyze the factors that influence attitudes toward online shopping. The results showed that perceived benefit and trust are the driving factors of consumer attitudes to make online purchases. Perceived benefit in this study also functions as a mediator in the influence of trust on attitude. This research finds that trust is the most influential factor in the attitude toward online shopping.

This study also produces findings that consumers who have a high level of trust have a positive attitude to online shopping compared to consumers who have a low level of trust. In consumers with high levels of trust, the emergence of a positive attitude is more influenced by trust. Whereas at the low level of trust, attitude is influenced by trust and perceived benefit, which is perceived benefit is the dominant factor. In these conditions, consumers see the system online as a technology that makes it easy for them to shop without needing to leave home. They are not too worried about their data as well as financial transactions because they can choose the delivery and payment system that is done by Cash on Delivery (COD). With this system, payments are made when the goods have been received by consumers so that consumers do not feel worried about losing money because the goods are not received.

The results of this study reveal that consumer attitudes towards the online shopping system are influenced by high and low-level consumer confidence. This shows that in an online system where sellers and buyers do not meet directly, trust has a significant role in reducing the risk of uncertainty. Online shops must maintain and enhance consumer trust so that positive attitudes arise in consumers.

The existence of a positive attitude will ultimately encourage online purchases. Consumer trust in the online system can be built with the excellent service provided by an online shop. The online shop must provide what consumers want following what has been promised. Reviews and product views that are generally given on website pages must be under reality. The difference between what is obtained by consumers with what has been promised by the online shop will be fatal and can cause consumers to have a negative attitude towards the online system.

Websites user interface that easy to access and operate must also be considered by online shops to build consumer trust. With the trust that has been built, consumers are expected to be able to feel the ease of making purchases using an online system. E-commerce also needs to explain in detail how to make transactions safely in an online system. Because the trust for consumers who have just adopted online shopping will depend on the completeness of the information and the ease of procedures in making available online transactions. This will reduce the risk of uncertainty and failure in online shopping. The type of payment system offered, and the security of financial transactions must also be considered. This means that if consumers get a payment system that he thinks is safe and reliable, then a positive attitude will arise in the consumer so that they will be interested in using the online system to purchase the desired product or service.

The theoretical contribution of this study is enriching knowledge related to consumer beliefs and attitudes towards online shopping. At any level, trust is an important factor influencing consumer attitudes in online shopping. Meanwhile, as a practical contribution, this study can be a reference for marketers to build consumer trust and increase the perceived benefits for online consumers.

\section{Funding}

This research did not receive any specific grant from funding agencies in the public, commercial, or not-for-profit sectors.

\section{References}

[1] D. A. Wren and A. G. Bedeian, The Evolution of Management Thought., Sixth. John Wiley\& Sons, Inc., 2009.

[2] K. Miyatake, T. Nemoto, S. Nakaharai, and K. Hayashi, "Reduction in Consumers' Purchasing Cost by Online Shopping," Transp. Res. Procedia, vol. 12, no. June 2015, pp. 656-666, 2016, DOI: 10.1016/j.trpro.2016.02.019.

[3] G. Punj, "Income effects on relative importance of two online purchase goals : Saving time versus saving money ?," J. Bus. Res., vol. 65, no. 5, pp. 634-640, 2012, doi: 10.1016/j.jbusres.2011.03.003.

[4] N. Vasic, M. Kilibarda, and T. Kaurin, "The Influence of 
Online Shopping Determinants on Customer Satisfaction in the Serbian Market," J. Theor. Appl. Electron. Commer. Res., vol. 14, no. 2, pp. 0-0, 2019, doi: $10.4067 / \mathrm{s} 0718-18762019000200107$.

[5] M. M. Al-Debei, M. N. Akroush, and M. I. Ashouri, "Consumer attitudes towards online shopping: The effects of trust, perceived benefits, and perceived web quality," Internet Res., vol. 25, no. 5, pp. 707-733, 2015, doi: 10.1108/IntR-05-2014-0146.

[6] C. Anton, C. Camamero, and Carrero, "Analyzing firms' failures as determinants of consumer switching intentions: The effect of moderating factors," Eur. J. Mark., vol. 41, no. 1/2, pp. 135-158, 2007, doi: 10.1179/str.2007.54.4.006.

[7] W. D. Hoyer and N. M. Ridgway, "Variety Seeking As an Explanation for Exploratory Purchase Behavior: a Theoretical Model.," Adv. Consum. Res., vol. 11, no. 1, pp. 114-119, 1984, [Online]. Available: http://search.ebscohost.com/login.aspx?direct=true\&db= bth\&AN $=6434113 \&$ site $=$ ehost-live.

[8] T. L. Huang and S. L. Liao, "Creating e-shopping multisensory flow experience through augmented-reality interactive technology," Internet Res., vol. 27, no. 2, pp. 449-475, 2017, doi: 10.1108/IntR-11-2015-0321.

[9] H. C. M. Van Trijp, W. D. Hoyer, and J. J. Inman, "Why switch? Product category-level explanations for true variety-seeking behavior," J. Mark. Res., vol. 33, no. 3, pp. 281-292, 1996, doi: 10.2307/3152125.

[10] M. B. Rao, "FACTORS AFFECTING FEMALE CONSUMER'S ONLINE BUYING BEHAVIOR," Acad. Mark. Stud. J., vol. 22, no. 2012, pp. 1-20, 2018.

[11] M. A. Rahman, M. A. Islam, B. H. Esha, N. Sultana, and S. Chakravorty, "Consumer buying behavior towards online shopping: An empirical study on Dhaka city, Bangladesh,” Cogent Bus. Manag., vol. 5, no. 1, pp. 1-22, 2018, doi: 10.1080/23311975.2018.1514940.

[12] A. Beldad, M. De Jong, and M. Steehouder, "How shall $\mathrm{i}$ trust the faceless and the intangible? A literature review on the antecedents of online trust," Comput. Human Behav., vol. 26, no. 5, pp. 857-869, 2010, doi: 10.1016/j.chb.2010.03.013.

[13] A. S. Al-Adwan and H. Kokash, "The driving forces of facebook social commerce," J. Theor. Appl. Electron. Commer. Res., vol. 14, no. 2, pp. 15-32, 2019, doi: 10.4067/S0718-18762019000200103.

[14] A. S. Al-Adwan, "Revealing the influential factors driving social commerce adoption," Interdiscip. J. Information, Knowledge, Manag., vol. 14, pp. 295-324, 2019, doi: $10.28945 / 4438$.

[15] M. N. Akroush and M. M. Al-Debei, “An integrated model of factors affecting consumer attitudes towards online shopping," Bus. Process Manag. J., vol. 21, no. 6, pp. 13531376, 2015, doi: 10.1108/BPMJ-02-2015-0022.

[16] D. Gefen, "E-commerce: The role of familiarity and trust," Omega, vol. 28, no. 6, pp. 725-737, 2000, doi: 10.1016/ S0305-0483(00)00021-9.

[17] E. Turban, D. King, J. K. Lee, T.-P. Liang, and D. C. Turban, Electronic Commerce A Managerial and Social Networks Perspective, Eighth. Springer, 2015.

[18] I. Ajzen and M. Fishbein, Understanding attitudes and predicting social behaviour. 1980.

[19] M. M. Al-Debei, E. Al-Lozi, and A. Papazafeiropoulou, "Why people keep coming back to Facebook: Explaining and predicting continuance participation from an extended theory of planned behaviour perspective," Decis. Support Syst., vol. 55, no. 1, pp. 43-54, 2013, doi: 10.1016/j.dss.2012.12.032.

[20] S. Agdaie, A. Piraman, and S. Fathi, "An analysis of factors affecting the consumer's attitude of trust and their impact on internet purchasing behavior,” Int. J. Bus. Soc. Sci., vol. 2, no. 23, pp. 147-158, 2011.

[21] J. Silva, J. C. Pinho, A. Soares, and E. SÁ, “Antecedents of online purchase intention and behaviour: Uncovering unobserved heterogeneity,” J. Bus. Econ. Manag., vol. 20, no. 1, pp. 131-148, 2019, doi: 10.3846/jbem.2019.7060.

[22] S. Yang, Y. Chen, and J. Wei, "Understanding consumers' web-mobile shopping extension behavior: A trust transfer perspective,” J. Comput. Inf. Syst., vol. 55, no. 2, pp. 78-87, 2015, doi: 10.1080/08874417.2015.11645759.

[23] L. Y. Zhang, Y. J. Shi, and Q. Lu, “Consumer's decision-making behavior in online shopping: An integrated analysis," Appl. Mech. Mater., vol. 519-520, pp. 420-427, 2014, doi: 10.4028/www.scientific.net/AMM.519-520.420.

[24] Y. A. O. Huili, L. I. U. Shanzhi, and Y. Yinghui, "A Study of User Adoption Factors of Mobile Banking Services Based on the Trust and Distrust Perspective," Int. Bus. Manag., vol. 6, no. 2, pp. 9-14, 2013, doi: 10.3968/j.ibm.1923842820130602.1040.

[25] D. J. Kim, D. L. Ferrin, and H. R. Rao, "A trust-based consumer decision-making model in electronic commerce: The role of trust, perceived risk, and their antecedents," Decis. Support Syst., vol. 44, no. 2, pp. 544-564, 2008, doi: 10.1016/j.dss.2007.07.001.

[26] M. Tingchi Liu, J. L. Brock, G. Cheng Shi, R. Chu, and T. H. Tseng, "Perceived benefits, perceived risk, and trust: Influences on consumers' group buying behaviour," Asia Pacific J. Mark. Logist., vol. 25, no. 2, pp. 225-248, 2013, doi: 10.1108/13555851311314031.

[27] Y. H. Tan and W. Thoen, "Toward a generic model of trust for electronic commerce," Int. J. Electron. Commer., vol. 5, no. 2, pp. 61-74, 2000, doi: 10.1080/10864415. 2000.11044201.

[28] J. P. Peter and J. C. Olson, Consumer Behavior \& Marketing Strategy. McGraw-Hill Irwin, 2010.

[29] M. Fishbein and I. Ajzen, Belief, Attitude, Intention, and Behavior: An Introduction to Theory and Research. MA: Addison-Wesley, 1975.

[30] S. Wu, "The relationship between consumer characteristics and attitude toward online shopping The relationship between consumer characteristics and attitude toward online shopping,” Mark. Intell. Plan., vol. 21, no. 1, pp. 37-44, 2003, doi: 10.1108/02634500310458135.

[31] I. Ajzen, "The theory of planned behavior," Organ. Behav. Hum. Decis. Process., vol. 50, no. 2, pp. 179-221, 1991.

[32] E. Al-Lozi, "Explaining users' intentions to continue participating in web 20 communities: the case of facebook in the hashemite kingdom of jordan,” Brunel University, 2011.

[33] T. Goodwin, "Measuring the effectiveness of online marketing,” Int. J. Mark. Res., vol. 41, no. 4, p. 403, 1999, doi: $10.1177 / 147078539904100404$.

[34] X. Cheng, S. Fu, Y. Han, and A. Zarifis, "Investigating the individual trust and school performance in semi-virtual collaboration groups," Inf. Technol. People, vol. 30, no. 3, pp. 691-707, 2017, doi: 10.1108/ITP-01-2016-0024.

[35] D. Gefen, "Reflections on the Dimensions of Trust and Trustworthiness among Online Consumers," Data Base Adv. Inf. Syst., vol. 33, no. 3, pp. 38-53, 2002, doi: $10.1145 / 569905.569910$.

[36] M. Brengman and F. P. Karimov, "The effect of web communities on consumers ' initial trust in B2C e-commerce websites," Manag. Res. Rev., vol. 35, no. 9, pp. 791-817, 2012, doi: 10.1108/01409171211256569.

[37] Y. B. Limbu, M. Wolf, and D. Lunsford, "Perceived ethics of online retailers and consumer behavioral intentions: The mediating roles of trust and attitude," J. Res. Interact. Mark., vol. 6, no. 2, pp. 133-154, 2012, doi: 10.1108/17505931211265435.

[38] M. A. Shareef, Y. K. Dwivedi, V. Kumar, G. Davies, N. Rana, and A. Baabdullah, "Purchase intention in an 
electronic commerce environment: A trade-off between controlling measures and operational performance," Inf. Technol. People, vol. 32, no. 6, pp. 1345-1375, 2019, doi: 10.1108/ITP-05-2018-0241.

[39] D. J. Kim, D. L. Ferrin, and H. R. Rao, "Trust And Satisfaction, Two Stepping Stones For Successful E-Commerce Relationships: A Longitudinal Exploration," Inf. Syst. Res., vol. 20, no. 2, pp. 237-257, 2009.

[40] J. P. Peter and L. X. Tarpey, "A comparative analysis of three consumer decision strategies., J. Consum. Res., vol. 2, no. 1, pp. 29-37, 1975, doi: 10.1086/208613.

[41] S. Forsythe, C. Liu, D. Shannon, and L. I. U. C. Gardner, "Development of a scale to measure the perceived benefits and risks of online shopping," J. Interact. Mark., vol. 20, no. 2, pp. 55-75, 2006, doi: 10.1002/dir.

[42] N. Souiden, S. Chtourou, and B. Korai, "Consumer Attitudes toward Online Advertising: The Moderating Role of Personality," J. Promot. Manag., vol. 23, no. 2, pp. 207-227, 2017, doi: 10.1080/10496491.2016.1267676.

[43] F. D. Davis, "Perceived Usefulness, Perceived Ease of Use, and User Acceptance of," MIS Q., vol. 13, no. 3, pp. 319-340, 1989, [Online]. Available: www.jstor.org/ stable/249008.

[44] B. Hernández, J. Jiménez, and M. J. Martín, “Age, gender and income: Do they really moderate online shopping behaviour?," Online Inf. Rev., vol. 35, no. 1, pp. 113-133, 2011, doi: 10.1108/14684521111113614.

[45] J. F. Hair Jr, W. C. Black, B. J. Babin, and R. E. Anderson, Multivariate Data Analysis, 7th ed. Pearson, 2014.

[46] Z. F. Chen and A. Occa, "How different CSR dimensions impact organization-employee relationships The moderating role of CSR-culture fit," Corp. Commun. An Int. J., vol. 24, no. 1, pp. 63-78, 2019, doi: 10.1108/ CCIJ-07-2018-0078.

[47] U. Akturan and N. Tezcan, "Mobile banking adoption of the youth market: Perceptions and intentions," Mark. Intell. Plan., vol. 30, no. 4, pp. 444-459, 2012, doi: 10.1108/02634501211231928.

[48] M. C. Lee, "Factors influencing the adoption of internet banking: An integration of TAM and TPB with perceived risk and perceived benefit," Electron. Commer. Res. Appl., vol. 8, no. 3, pp. 130-141, 2009, doi: 10.1016/ j.elerap.2008.11.006.

[49] S. K. Ariffin, T. Mohan, and Y. Goh, "In fl uence of consumers 'perceived risk on consumers' online purchase intention,” J. Res. Interact. Mark., vol. 12, no. 3, pp. 309-327, 2018, doi: 10.1108/JRIM-11-2017-0100.

[50] S. ur Rahman, M. A. Khan, and N. Iqbal, "Motivations and barriers to purchasing online: understanding consumer responses," South Asian J. Bus. Stud., vol. 7, no. 1, pp. 111-128, 2018, doi: 10.1108/SAJBS-11-2016-0088.

[51] S. Kim and M. S. Eastin, "Hedonic tendencies and the online consumer: An investigation of the online shopping process," J. Internet Commer., vol. 10, no. 1, pp. 68-90, 2011, doi: 10.1080/15332861.2011.558458.

[52] H. Van Der Heijden, T. Verhagen, and M. Creemers, "Understanding online purchase intentions: Contributions from technology and trust perspectives,” Eur. J. Inf. Syst., vol. 12, no. 1, pp. 41-48, 2003, doi: 10.1057/palgrave.ejis. 3000445 .

[53] S. L. Jarvenpaa, N. Tractinsky, and L. Saarinen, "Consumer Trust in an Internet Store: A Cross-Cultural Validation," J. Comput. Commun., vol. 5, no. 2, pp. 0-0, 2006, doi: 10.1111/j.1083-6101.1999.tb00337.x.

[54] C. Yu and C.-K. Li, "Analysis of Consumer E-Lifestyles and Their Effects on Consumer Resistance to Using Mobile Banking: Empirical Surveys in Thailand and Taiwan," Int. J. Bus. Inf., vol. 10, no. 2, pp. 198-232, 2015.

[55] A. Frik and L. Mittone, "Factors Influencing the
Perception of Website Privacy Trustworthiness and Users' Purchasing Intentions: The Behavioral Economics Perspective," J. Theor. Appl. Electron. Commer. Res., vol. 14, no. 3, pp. 89-125, 2019, doi: 10.4067/s071818762019000300107.

[56] N. Arora and A. Aggarwal, "The role of perceived benefits in formation of online shopping attitude among women shoppers in India," South Asian J. Bus. Stud., vol. 7, no. 1, pp. 91-110, 2018, doi: 10.1108/SAJBS-04-2017-0048. 